\title{
Impact of Using the Internet on Students: A Sociological Analysis at Bangabandhu Sheikh Mujibur Rahman Science and Technology University, Gopalganj, Bangladesh
}

\author{
Kaniz Fatema ${ }^{1 *}$, Shamima Nasreen1, Md. Shahin Parvez ${ }^{1}\left(\mathbb{C}\right.$, Md. Anisur Rahaman $^{1,2}$ \\ ${ }^{1}$ Department of Sociology, Bangabandhu Sheikh Mujibur Rahman Science and Technology University, Gopalganj, Bangladesh \\ ${ }^{2}$ College of Public Administration, Zhejiang University, Hangzhou, China \\ Email: ${ }^{\star}$ fatemabsmrstu037@gmail.com
}

How to cite this paper: Fatema, K., Nasreen, S., Parvez, Md. S., \& Rahaman, Md. A. (2020). Impact of Using the Internet on Students: A Sociological Analysis at Bangabandhu Sheikh Mujibur Rahman Science and Technology University, Gopalganj, Bangladesh. Open Journal of Social Sciences, 8 , 71-83.

https://doi.org/10.4236/jss.2020.812007

Received: November 2, 2020

Accepted: December 7, 2020

Published: December 10, 2020

Copyright $\odot 2020$ by author(s) and Scientific Research Publishing Inc. This work is licensed under the Creative Commons Attribution International License (CC BY 4.0).

http://creativecommons.org/licenses/by/4.0/

\section{(c) (i) Open Access}

\begin{abstract}
This is an exploratory research to examine the possible impact of using the internet on students' academic, personal and social life. Quantitative and qualitative methods were used in this study. For collecting quantitative data, a total of 85 samples were drawn purposively and interviewed using a semi-structured questionnaire. In addition, 2 case studies were conducted for the qualitative part of this study. Findings reveal that almost every student in the study area uses the internet to some degree. From the study it is found that about $56 \%$ of respondents use the internet for educational purpose, $24 \%$ of them use the internet only for recreation and $44 \%$ were found who use the internet to browse social networking sites. The study also indicates that the majority of the students use the internet for 0 - 4 hours per day. A significant proportion of the respondents said that the internet can positively enhance their academic performance and as well as improve their quality of life. On the other hand, results have shown that internet addiction has a negative impact on students' academic performance and social life. Overall, the internet plays a vital role in improving students' academic performance and quality of life.
\end{abstract}

\section{Keywords}

Internet, Students, BSMRSTU, Bangladesh

\section{Introduction}

The internet is one of the greatest recent advancements in the world of information technology and has become a useful instrument that has advanced the 
process of making the world a global village. This is a global fact that the use of the internet has a major impact on the student's academic achievement and social life (Asdaque, Khan, \& Rizvi, 2010). Despite the positive impact of the internet on academic performance, research findings have shown that excessive internet usage negatively affects one's physical health, family life and academic performance (Akhter, 2013). Along with the stunning increase of the internet and its use, there has been a growing concern worldwide regarding the risks connected with internet over-use (Buchholz, 2009). Students have only lately received the chance to use the internet to seek and obtain scholarly material and, consequently, knowledge on how successfully they make use of this channel is limited. Students' information-seeking ends as they work on their theses (Tenopir et al., 2003). According to Asdaque, Khan, \& Rizvi (2010) the use of the internet is one of the major factors affecting the academic performance and social life of university students. The number of hours spent on the internet will affect the grades of students depending on if the internet is used for study purpose or social motive. A study has shown that the university student on average spends 30 minutes to 2 hours on Facebook/day (Knibbe \& Luchies, 2013). Also, students can obtain from others' knowledge and experiences, participate in chat rooms, share ideas and solutions. Studies have shown that an increase in virtual interaction lessens the amount of face-to-face interaction between people and this in turn may breed social isolation and depression (Mythily, Qiu, \& Winslow, 2008). It was observed in a study that the time spent on online social networking is associated with depression. The authors noted an increase in depression scores as the time spent on social networks has been increased (Balouch, et al., 2019). Generally, the students of tertiary education level use the internet for various purposes including academic, social communication and recreation. In a word it can be said that they use the internet in every sphere of daily life. As a result, their behavioral pattern is changing very rapidly. As well as cultural change, their social and economic life also is reorganized by using such type of technology. Therefore, as per objectives this research specifically aims to examine the impact of using the internet on students of Bangabandhu Sheikh Mujibur Rahman Science and Technology University, Gopalganj, Bangladesh. The study is carried out with the following objectives, i.e. to know the accessibility of the internet among students; to know the purpose of using the internet by students; to find the positive and negative aspects of internet use among students.

\section{Literature Review}

Asdaque et al. (2010) stated that the spread of the internet has reformed the academic and social life of students with greatest advancement. They argued that the internet is useful mechanism to make today's world into a global village. It is common fact that the internet has a great impact on students' academic, personal and social life. They found that the use of the internet affects the academic achievement and social life of university students'. Academic achievement is basically influenced by time spending with the internet. In this research academic 
achievement is measured by CGPA. This study explored that if students spend more time on study purpose than social media, the CGPA is good and vice-versa. Extreme use of the internet by university students reduces their social activities.

Ivwighreghweta \& Igere (2014) in their study stated that most of the students have internet access and they are skillful in using the internet. This study found that maximum students use the internet on academic pursuit including collect reading materials, preparing for examination and encouraging research work. The authors argued that the internet is regarded as the new tool of learning, also exceed the impotence and information of physical library. This study also identified that students face some challenges in using the internet i.e. low internet speed, power outage and information overload.

Jackson, Eye \& Biocca (2003) found that about 30 minutes are spent by the children and more surprisingly, they do not use internet on communication purpose. Mainly two types of social outcomes are discovered in their study. Firstly, children use the internet for strengthening the communication with those people who are physically be present in distance. On the other hand, this virtual communication somehow decreases face-to-face relationship with family and friends. They also revealed that CGPA is high of those students who use the internet.

Saha \& Guha (2019) noticed that the internet has been raised tremendously as a platform of communication among the young generation. Most of the students have possession of the internet through mobile phone. Students use internet at least one hour per day for chatting. Use of the internet and social media has both positive and negative impact on students' social life. Internet is used for communication and news updates. Sometimes heavy use of the internet leads to waste of time and depression among students. This study concluded that use of the internet and social media lead to healthy life and enrich learning practice.

Talooki, Ataee, Gorji \& Aghaei (2017) indicate that use of the internet may effect on students 'behavioral pattern. Not only behavior, using the internet has a great impact on all aspect of human life including personal, social, political, economic and academic life. By using this sophisticated tool, students can communicate with other, collect study materials, understanding cultural phenomenon and so on. But use of excessive internet has badly affect students' life. Waste of time, depression and isolation, unemployment, misplacing social bonding and Physical abnormalities are caused by heavy internet use.

\section{Methodology}

Methodology is the systematic, theoretical analysis of the methods applied to a field of study. It comprises the theoretical analysis of the body of methods and principals associated with a branch of knowledge. Typically, it encompasses concepts such as philosophical or theoretical framework, theoretical model, phases and quantitative or qualitative techniques.

\subsection{Nature of the Study}

Using survey research method, both qualitative and quantitative data were col- 
lected from the university level residing in Bangabandhu Sheikh Mujibur Rahman Science and Technology University, Gopalganj, Bangladesh.

\subsection{Method of the Study}

There are several methods in sociology. These are social survey method, Observation Method, Case Study Method, Anthropological Method, Comparative method, Philosophical Analysis, content analysis, Statistical method etc. We were used different methods for the purpose of collecting holistic information. Generally, we used survey method for preparing questionnaire as well as case study method for in-depth analysis.

\subsection{Study Area}

The study area is selected purposefully on the basis of objectives of the study. The study area included Bangabandhu Sheikh Mujibur Rahman Science and Technology University, Gopalganj, Bangladesh.

\subsection{Unit of Analysis}

Unit of analysis is an important factor for conducting any research. It is the "what" or "who" that is being studied. In social science research, typically the unit of analysis includes individual, groups, social organization and social artifacts. To achieve the objective of the study data were collected from the students of university level.

\subsection{Population of the Study}

After identifying the unit of analysis, then we have to identify the target population, the group of people that we want to draw a conclusion about once the research study was finished. Identifying the target population requires specifying the criteria that determines which individuals are not included. Data were collected from the students of Bangabandhu Sheikh Mujibur Rahman Science and Technology University.

\subsection{Sampling Procedure of the Study}

For this study, data were collected from Bangabandhu Sheikh Mujibur Rahman Science and Technology University, Gopalganj, Bangladesh. Firstly, purposefully the educational institution was selected. Then, by using simple random sampling technique, sample size (85) was identified from the total population. In this method, each observation has an equal probability of being selected, therefore, the sample taken is very much representative.

\subsection{Source of Data}

To prepare the study properly available and reliable data are very much essential. To conduct the study two types of data sources are utilized, the first is primary data i.e. field surveys. The other data source is secondary materials, relevant to the study. These sources are online journal, newspaper, thesis papers, articles, 
books, seminar papers, various online websites.

\subsection{Techniques of Data Collection}

The study is mainly dependent on primary data. Some secondary data have also been. Quantitative data have been collected through semi-structured interview questionnaire as a part of survey method. On the other hand, a checklist for the case studies has been used as the tools of the research.

\subsection{Development of Study Instrument(s)}

Primarily, an interview schedule was developed and given to the supervisor for correction. Corrected interview schedule was primarily applied for data collection through pilot survey. Some problems were identified during the pre-test and then edited correctly. According to the problems as identified during pre-test, interview schedule was developed with the suggestion of the supervisor. Finally, modified interview schedule was employed for data collection from the study area.

\subsection{Processing of Data}

For the study purpose, the data were processed with the start of encoding of the primary data. In the time of data procession, some data error correction, data management, standardization, scaling and other procedures have been done. In this case, tabulation method implying comparative study of different variables has been used. For doing this, different statistical software such as Statistical Package for Social Science (SPSS), Microsoft Excel have been used. In order to draft the whole paper, Microsoft Word was used. The quantitative data have also been prepared according to the need and objective of the research. After completing the processing, the data were analyzed and prepared for the final presentation of major study findings. In order to ensure the data validity of the study result, some careful measurements were taken.

\subsection{Analysis and Interpretation of Data}

After processing the data, analysis and interpretation were done by using statistical techniques.

\section{Findings of the Study}

\subsection{Age of the Respondents}

It is seen that the age of the respondent is a vital factor to appreciate the different social and cultural phenomena in different situations of society. Respondents are selected from different ages in this study. This research is basically done on tertiary level students. Here respondents are selected from honors first year to honors final year whose age is around the $18-24$.

\subsection{Academic Year of the Respondents}

Table 1 presents the educational level of the respondents. It is necessary to know 
Table 1. Percentage distribution of respondents according to academic year.

\begin{tabular}{ccc}
\hline Academic year & Frequency & Percentage \\
\hline $1^{\text {st }}$ Year & 20 & 24 \\
$2^{\text {nd }}$ Year & 20 & 24 \\
$3^{\text {rd }}$ Year & 15 & 17 \\
$4^{\text {th }}$ Year & 15 & 17 \\
Masters & 15 & 18 \\
\hline
\end{tabular}

about the educational level of the respondents to evaluate this research fruitfully. This table represents the educational year of the respondents. Here $20 \%$ of students are remaining in first year, $18 \%$ of respondents are second year, $32 \%$ of respondents are third year and 30\% of respondents are fourth year.

\subsection{Accessibility of the Internet among Respondents}

Figure 1 illustrates the percentage distribution of the internet users. Here in this figure, it is identified those respondents who are using the internet and who are not. This figure has shown that most of the respondents have their internet access on their own and they also use the internet on a regular basis. About $94 \%$ of respondents are using the internet actively whereas $6 \%$ of respondents are not involved in internet using, they have no internet access.

\subsection{Distributions of the Time Students Spend with the Internet}

Table 2 shows the average hours students spend on the internet per day. Due to the rapid spread of different types of technological devices, the use of the internet has been enhanced rapidly. Students spend a long period of time using the internet whether it may be for academic purposes or recreational purposes. For investigating the overall impact of the internet on students, it is very important to know the average time of internet use per day by the respondents. Thirty-two-point-nine percent of respondents use the internet 0 - 1 hour per day whereas 2 - 4 hours/day are used by $40 \%$ respondents. $11.8 \%$ respondents said that they use the internet 5 6 hours per day and $5.9 \%$ of them use 7 to 9 hours a day. $3.5 \%$ of respondents have found who spend more than 10 hours per day on the internet.

\subsection{Type of Internet User Categorized by Internet Addiction}

Here in Figure 2, it represents the types of internet user categorized by internet addiction. Internet addiction is defined by too many urges or behaviors regarding computer use and internet access that lead to damage or distress (Shaw, 2008). Internet addiction is also called compulsive computer use, pathological internet use, and internet dependence (Addiction Center, 2019). While internet addiction is a broad term, there are no general criteria to accept the categorization of internet addiction. Several researchers classified internet addiction in a different way. Previous research shows that the person who uses 16 hours/more 
Table 2. Spending hour on using the internet by the respondents.

\begin{tabular}{ccc}
\hline Spending Hour & Frequency & Percentage (\%) \\
\hline $\mathbf{0}$ to hour/day & 28 & 32.9 \\
$\mathbf{2}$ to 4 hours/day & 34 & 40.0 \\
$\mathbf{5}$ to 6 hours/day & 10 & 11.8 \\
$\mathbf{7}$ to 9 hours/day & 5 & 5.9 \\
$\mathbf{1 0}+$ hours/day & 3 & 3.5 \\
\hline
\end{tabular}

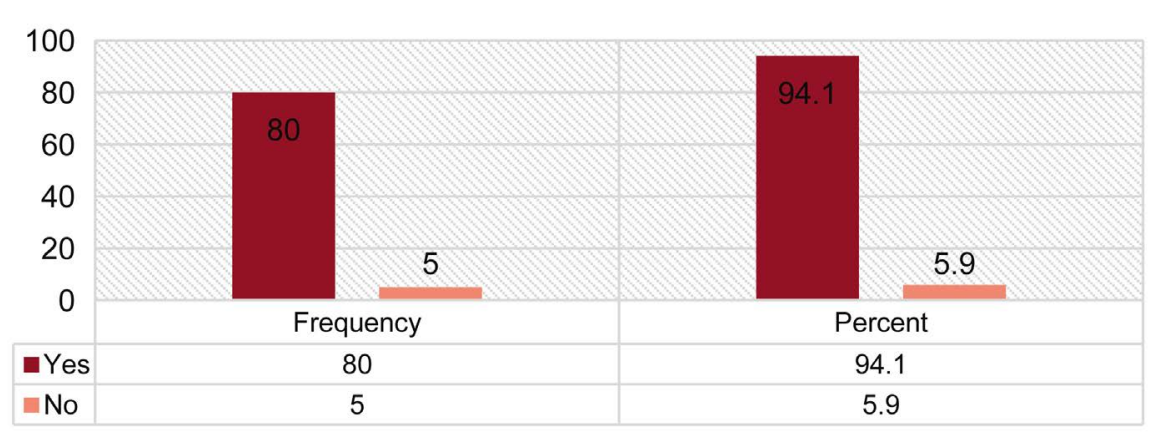

Figure 1. Accessibility of the internet among respondents.

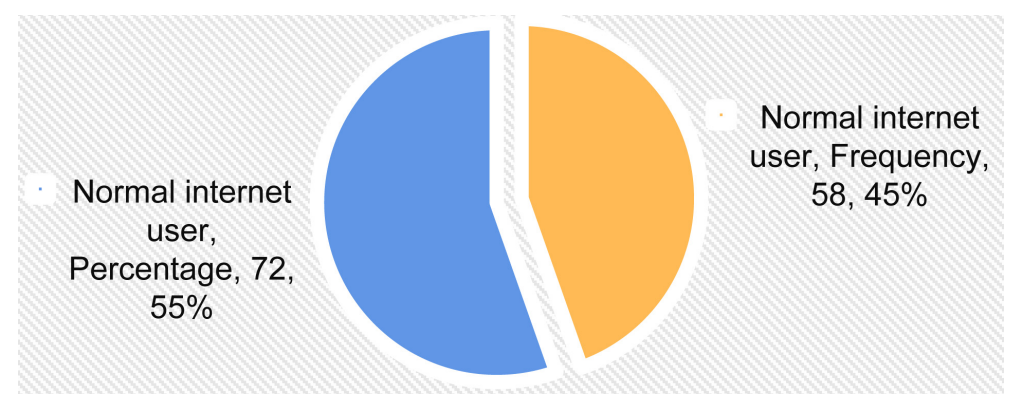

Figure 2. Type of internet user categorized by internet addiction.

than of it is called a heavy addictive internet user, who uses 3 - 16 hour/day is a moderate addictive user, and who uses less than three hours is a light user (Webroot, 2020). In this research, we make this arrangement depending on spending hours with the internet and computer. Internet addiction has been associated with dimensionally measured depression and indicators of social isolation (Shaw, 2008). We classify internet users into two types based on previous research, i.e. normal internet user and the addictive user because there were no respondents in this research who use the internet more than 16 hours/day. Here clearly identified that most of the students use the internet on a general basis or for normal purposes. But, in this research, some students have an infatuation with internet use. Overall, most of the respondents use the internet for academic purposes. When they use it for relaxation (i.e. social networking sites, motivational videos, video games), it leads to internet addiction. Among the respondents, $73 \%$ are using the internet on a normal basis, and $28 \%$ of respondents using the internet addictively. 


\subsection{Respondents Possession of Technologies}

Table 3 represents the types of technological devices are used by the respondents. Most of the respondents (67.5\%) like to use the internet on smartphones because a smartphone is bearable and its functions are also too much easy to understand. Here $6.2 \%$ of the respondents use desktop whereas $18.8 \%$ of respondents use laptops. Only $7.5 \%$ of them have been found who use tablets.

\subsection{Respondents Purposes of Using the Internet}

The internet is now a global network in which human beings in every sphere are related to each other. Moreover, the internet has both positive and negative impacts on students' life. Students use the internet for various purposes. In previous studies, it is identified that students basically use the internet for the purpose of academic and social betterment but sometimes they become addicted to it when they have free time or when they need emotional support. One of the main objectives of this study is to explore the purposes of using the internet by respondents. Table 4 represents the purposes of using the internet by respondents. From the study it is found that students use the internet for multiple purposes. Among total respondents $56 \%$ use the internet for academic or educational purpose, $24 \%$ of the respondents use the internet only for recreational purpose whereas $44 \%$ of the respondents use social networking sites on the internet. On the other hand, a significant proportion $(76 \%)$ of the respondents said that they use the internet for other purposes like online Shopping, booking ticket and so on.

\subsection{Academic Purposes of Using the Internet}

From this study, it is found that most of the respondents of this study use the internet for academic purposes. Among the academic purposes, there are different areas of interest. The following table represents the different purposes of the academic use of the internet. From Table 5 it is found that $59 \%$ of the respondents complete their required course work with the help of the internet, $29 \%$ of the respondents use the internet to do research work. Internet is also used by $33 \%$ of the respondents for completing home task, assignments and course works assigned by the course teachers. $66 \%$ of the respondents use the internet for reading books and collecting the required study materials.

\subsection{Internet Tools and Resources Used by the Respondents}

This study found that most of the respondents in this study have internet access. They use various tools and resources for browsing the internet. The following Table 6 shows the tools and resources that are used by the respondents. In this study it is found that $78 \%$ of respondents use Facebook while $22 \%$ of them have not any Facebook account and 27\% of the respondents use Twitter, $26 \%$ of the respondents have an E-mail account. Google is used by $41 \%$ of the respondents. YouTube is used by $38 \%$ of respondents, Skype is used by $12 \%$ of the respondents, and Google maps is used by $19 \%$ of the respondents. 
Table 3. Respondents possession of technologies.

\begin{tabular}{ccc}
\hline Device & Frequency & Percentage (\%) \\
\hline Desktop & 5 & 6.2 \\
Laptop & 15 & 18.8 \\
Tablets & 6 & 7.5 \\
Smart Phone & 54 & 67.5 \\
\hline
\end{tabular}

Table 4. Distributions of the respondents according to the purposes of using the internet.

\begin{tabular}{ccccccc}
\hline \multirow{2}{*}{ Purpose } & \multicolumn{2}{c}{ Yes } & \multicolumn{2}{c}{ No } & \multicolumn{3}{c}{ Total } \\
\cline { 2 - 7 } & Frequency & $\%$ & Frequency & $\%$ & Frequency & $\%$ \\
\hline Academic/Educational purpose & 48 & 56 & 32 & 44 & 80 & 100 \\
Recreation or Relaxation & 20 & 24 & 60 & 76 & 80 & 100 \\
Using Social Networking Sites & 37 & 44 & 43 & 56 & 80 & 100 \\
Others & 65 & 76 & 15 & 24 & 80 & 100 \\
\hline
\end{tabular}

Table 5. Academic purposes of using the internet.

\begin{tabular}{|c|c|c|c|c|c|c|}
\hline \multirow{2}{*}{ Academic purpose } & \multicolumn{2}{|c|}{ Yes } & \multicolumn{2}{|l|}{ No } & \multicolumn{2}{|c|}{ Total } \\
\hline & Frequency & $\%$ & Frequency & $\%$ & Frequency & $\%$ \\
\hline Required course work & 50 & 59 & 30 & 41 & 80 & 100 \\
\hline Doing research work & 25 & 29 & 55 & 71 & 80 & 100 \\
\hline $\begin{array}{l}\text { Completing assignments and } \\
\text { course works }\end{array}$ & 28 & 33 & 52 & 67 & 80 & 100 \\
\hline $\begin{array}{l}\text { Reading books and collecting } \\
\text { required study materials }\end{array}$ & 56 & 66 & 24 & 34 & 80 & 100 \\
\hline
\end{tabular}

Table 6. Internet tools and resources used by the respondents.

\begin{tabular}{ccccccc}
\hline \multirow{2}{*}{ Tools and resources } & \multicolumn{2}{c}{ Yes } & \multicolumn{2}{c}{ No } & \multicolumn{2}{c}{ Total } \\
\cline { 2 - 7 } & Frequency & $\%$ & Frequency & $\%$ & Frequency & $\%$ \\
\hline Face book & 66 & 78 & 14 & 22 & 80 & 100 \\
Twitter & 17 & 27 & 63 & 73 & 80 & 100 \\
E-mail & 22 & 26 & 58 & 74 & 80 & 100 \\
Google & 35 & 41 & 45 & 59 & 80 & 100 \\
You Tube & 32 & 38 & 70 & 88 & 80 & 100 \\
Skype & 10 & 12 & 48 & 62 & 80 & 100 \\
Google map & 16 & 19 & 64 & 81 & 80 & 100 \\
\hline
\end{tabular}

\subsection{Addictive Internet Usage Decreases Face to Face Relationship with Family}

Table 7 represents the percentage distributions of the respondents according to their opinion on the impact of excessive use of the internet on face to face inte- 
raction and interpersonal relationship. 17.6\% of respondents are found who have strongly agreed that addictive internet use decreases face to face relationship where $47.1 \%$ of respondents have agreed with this statement. On contrast, $10.6 \%$ of students have disagreed and only $1.2 \%$ have strongly disagreed.

\subsection{Impact of Internet Addiction on Students' Academic Performance}

Table 8 shows the percentage distributions of the respondents according to their opinion on the negative impact of internet addiction on students' academic performance. Internet is regarded as an important tool in this technological era. But abuse of the internet by students has negative impact on their life. In this research, respondents were asked to opine "Internet addiction affects negatively on the academic achievement of students". $42.5 \%$ of respondents have strongly agreed with this statement and $21.5 \%$ of them have agreed. Whereas $18.75 \%$ of respondents were in neutral position, $5 \%$ have strongly disagreed and $7.5 \%$ have disagreed.

\subsection{Internet Usage Improves Social Life}

Table 9 represents the importance of using the internet for enhancing the quality

Table 7. Addictive internet usage decreases face to face relationship with family.

\begin{tabular}{ccc}
\hline Opinion of respondents & Frequency & Percentage (\%) \\
\hline Strongly Agree & 15 & 17.6 \\
Agree & 40 & 47.1 \\
Neutral & 15 & 17.6 \\
Strongly Disagree & 9 & 10.6 \\
Disagree & 1 & 2.0 \\
\hline
\end{tabular}

Table 8. Impact of internet addiction on students' academic performance.

\begin{tabular}{ccc}
\hline Opinion of respondents & Frequency & Percentage (\%) \\
\hline Strongly Agree & 34 & 42.5 \\
Agree & 21 & 21.25 \\
Neutral & 15 & 18.75 \\
Strongly Disagree & 4 & 5 \\
Disagree & 6 & 7.5 \\
\hline
\end{tabular}

Table 9. Internet usage improves social life.

\begin{tabular}{ccc}
\hline Respondents opinion & Frequency & Percentage (\%) \\
\hline Strongly Agree & 26 & 32.0 \\
Agree & 43 & 54.0 \\
Neutral & 11 & 14.0 \\
Strongly Disagree & 0 & 0.0 \\
Disagree & 0 & 0.0 \\
\hline
\end{tabular}


of social life. Some researchers argued that the internet affects peoples' lives by increasing communication, expanding educational services, and improving quality of life along with personal interaction. Here $32 \%$ of respondents have strongly agreed that internet use enhances the quality of social life, whereas $54 \%$ of respondents neither agreed nor disagreed and $14 \%$ disagreed.

\section{Discussion of the Study}

Analysis in chapter four shows that the internet has both positive and negative impact on students. This study consists of 85 respondents. Here respondents are selected from honors first year to honors final year whose age is around the 18 24 . About $94 \%$ of respondents use the internet actively whereas $6 \%$ of them are not involved in the internet using. Here, according to the cultural lag theory, those people who do not use the internet cannot develop their psychology or ideology, and there creates a gap between material culture and non-material culture. Among the respondents, $73 \%$ use the internet on a normal basis, and $28 \%$ of respondents are found who use the internet addictively. Mariek M. P. Vanden Abeele argued that uncontrolled use of the internet may hamper youths' performance in academic and social life (Abeele, 2015). Thirty-two-point-nine percent of respondents use the internet 0 - 1 hour per day, $2-4$ hours/day are spent on the internet by $40 \%$ respondents. $11.8 \%$ of respondents have found who use internet $5-6$ hours/day and $7-9$ hours/day are spent on the internet by $5.9 \%$ of respondents. Above 10 hours are spent by $3.5 \%$ of respondents per day. Here $6.2 \%$ of the respondents use desktop, $18.8 \%$ of respondents use laptops, $7.5 \%$ use tablets, and about $67.5 \%$ use smartphones. The study has found that among total respondents $56 \%$ use the internet for academic or educational purpose, $24 \%$ of the respondents use the internet only for recreational or relaxation purpose, and $44 \%$ of the respondents use social networking sites through browsing the internet. From this study, it is found that most of the respondents use Facebook, Twitter, Google, YouTube, and e-mail. Here 32\% of respondents strongly agreed that internet use increases the quality of social life, whereas $54 \%$ of respondents neither agreed nor disagreed and $14 \%$ have disagreed. $17.6 \%$ of respondents strongly agreed that excessive use of the internet hampers academic performance and decreases face-to-face relationship or weakening interpersonal relations. One of the respondents of in-depth interviews said, "I think gradually we are being separated from our friends and family. Previously when we usually went the home, we employed all of our time with my family and friends, but now we are departed from them for using technologies. And it decreases our traditional social gathering and face to face relationship". The Internet played a pivotal role in the contextual academic, personal and social life of students. Internet provides opportunities to do the required course work, do the research work, complete assignment, collect materials for study in search engine and so on. These all help students to improve academic performance. On the other hand, addictive internet usage could negatively have stuck students' academic 
performance. Excessive internet usage decreases face to face relationship with family and friends. However, the quality uses of the internet depend on the respective study context in terms of available accessibility of the Internet, individual skills, and affordability of users.

\section{Conclusion}

The conclusion that can be drawn from this research is that internet usage is the factor that influences students' life both positively and negatively including academic performance, personal and social life. Graphical representation of internet usage and its impact on students shows the internet accessibility, spending hours in using the internet, purposes of using the internet, and impact of using the internet on students' academic achievement, face to face relationship with their friends and families. Positive and negative impact of using the internet is proportionally equal in this study. Here, positive outcome includes academic achievement (completing course work and research work, searching in search engine for study materials, completing assignments and so on) and improving the quality of social life. Negative impacts are internet addiction, lack of face to face communication, waste of time, excessive use of social networking sites and depression. The study recommends that as the internet is regarded as an inseparable part of human life, students should conscious of using the internet. Seminars and conferences should be arranged to highlight the negative impact of using the internet on students. However, the quality uses of the internet depend on the respective study context in terms of available accessibility of the internet, individual skills and affordability of users.

\section{Acknowledgements}

First of all, our deepest gratitude to the Almighty Allah who enabled us to be success overcoming all shortcomings to complete this research. We would like to convey our debt of gratefulness to our honorable supervisor Shamima Nasreen, Assistant Professor, Department of Sociology at Bangabandhu Sheikh Mujibur Rahman Science and Technology University, Gopalganj, Bangladesh whose generous guidance, attention, and particularly untiring encouragement always kept our perplexed thoughts towards an appropriate direction. Finally, we want to express our unconditional thanks to those who shared their busy moment providing required information during field survey.

\section{Conflicts of Interest}

The authors declare no conflict of interest regarding the publication of this paper.

\section{References}

Abeele, M. M. (2015). Mobile Youth Culture: A Conceptual Development. SAGE Journal: Mobile Media \& Communication, 4, 85-101. 
https://doi.org/10.1177/2050157915601455

Addiction Center (2019). Internet Addiction. https://www.addictioncenter.com/drugs/internet-addiction/

Akhter, N. (2013). Relationship between Internet Addiction and Academic Performance among University Undergraduates. Journal of Science and Technology Education Research, 8, 1793-1796.

Asdaque, M. M., Khan, M. N., \& Rizvi, D. S. (2010). Effect of Internet on the Academic Performance and Social Life of University Students in Pakistan. Journal of Education and Sociology, 12, 21-27.

Balouch, D. A., Anwar, D., Amsari, M. I., Rasheed, D. T., Siddique, M., \& Balouch, D. N. (2019). Impact of Online Social Networking on Mental Health among Medical Students of LUMHS Jamshoro, Sindh, Pakistan. Rawal Medical Journal, 44, 613-617.

Buchholz, L. (2009). Teen Internet Addicts More Likely to Self-Harm.

Ivwighreghweta, O., \& Igere, M. A. (2014). Impact of the Internet on Academic Performance of Students in Tertiary Institutions in Nigeria. Journal of Information and Knowledge Management, 5, 47-56.

Jackson, L. A., Eye, A., \& Biocca, F. (2003). Children and Internet Use: Social, Psychological and Academic Consequences for Low-Income Children. Washington DC: American Psychological Association. https://doi.org/10.1037/e322302004-004

Knibbe, T. J., \& Luchies, L. (2013). Motivations to Use Facebook for New Relationships Predicts Poorer Well-Being among Extraverts but Better Well-Being among Introverts. Journal of Interpersonal Relations, Intergroup Relations and Identity, 6, 16-27.

Mythily, S., Qiu, S., \& Winslow, M. (2008). Prevalence and Correlates of Excessive. Annals of the Academy of Medicine, 37, 9-14.

Saha, S. R., \& Guha, A. K. (2019). Impact of Social Media Use of University Students. International Journal of Statistics and Applications, 9, 36-43.

Shaw, M. (2008). Internet Addiction: Definition, Assessment, Epidemiology and Clinical Management. CNS Drugs, 22, 353-365.

https://doi.org/10.2165/00023210-200822050-00001

Talooki, N. N., Ataee, M., Gorji, M. A. H., \& Aghaei, N. (2017). The Role of Regular Internet Usage on Social Behavior of Students. Indian Journal of Social Psychiatry, 33, 53-56. https://doi.org/10.4103/0971-9962.200094

Tenopir, C., King, D., Boyce, P., Grayson, M., Zhang, Y., \& Ebuen, M. (2003). Patterns of Journal Use by Scientists through Three Evolutionary Phases. D-Lib Magazine, 9. https://doi.org/10.1045/may2003-king

Webroot (2020). Internet Addiction: How Much Is Too Much Time Online? https://www.webroot.com/us/en/resources/tips-articles/internet-addiction-too-much-ti $\underline{\text { me-online }}$ 